\title{
Impact of Pro-Oxidant Agents on the Morula-Blastocyst Transition in Bovine Embryos
}

\author{
JEAN-MAGLOIRE FEUGANG ${ }^{1}{ }^{1 S A B E L L E ~ D O N N A Y, ~}{ }^{1 *}$ PASCAL MERMILLOD,${ }^{2}$ \\ JOELLE MARCHANDISE, ${ }^{1}$ AND ANNE-SOPHIE LEQUARRE ${ }^{1}$ \\ ${ }^{1}$ Unité des Sciences vétérinaires, Institut des Sciences de la Vie, Université catholique de Louvain, \\ Louvain-la-Neuve, Belgium \\ ${ }^{2}$ INRA, Station de Physiologie de la Reproduction, Centre de Recherches de Tours, Nouzilly, France
}

\begin{abstract}
Exposing day 5 bovine morulae to reactive oxygen species induces a delayed degeneration of some blastocysts on day 8 post-insemination (pi) but without affecting the blastocyst rates. The aim of this study was to characterize the resisting and the degenerating population of blastocysts. The kinetics of degeneration of the embryos exposed to the two prooxidant agents: 2,2'-azobis (2-amidinopropane) dihydrochloride (AAPH) and buthionine sulfoximine (BSO) was evaluated using time-lapse cinematography. With both agents the first signs of degeneration appeared at day 7.5 pi but the duration of the degeneration process was shorter in presence of AAPH than BSO (4.2 vs. $12.5 \mathrm{hr}$, ANOVA, $P<0.05)$. The resisting blastocysts derived from morulae with a larger diameter (mean diameter: 161 vs. $154 \mu \mathrm{m}$, ANOVA, $P<0.05)$ and showed an earlier cavitation (135 vs. 142 hpi, $P<0.05)$ than the degenerating ones. The profile of protein neosynthesis at day 7 was not affected by the treatment. The proportion of male embryos was more important in the resisting than in the degenerating population (70 vs. $55 \%, \chi^{2}, P<0.05$ ) especially when the stress was induced by AAPH. The quality of the resisting embryos, measured by the total cell number and the rate of apoptosis, did not seem to be affected when compared to control embryos. In conclusion, resistance to oxidative stress seems related to the kinetics of development and/or the sex of the embryos. Resisting embryos apparently display a quality similar to untreated embryos. Mol. Reprod. Dev. 71: 339-346, 2005. (c) 2005 Wiley-Liss, Inc.
\end{abstract}

Key Words: bovine embryo; oxidative stress; apoptosis; sex-ratio; IVF

\section{INTRODUCTION}

Culture conditions are known to influence the kinetics of development (Carolan et al., 1995; Van Langendonckt et al., 1997), protein content (Thompson et al., 1998), and sex ratio (Avery et al., 1991; Peippo et al., 2001) of in vitro produced bovine embryos. Some culture systems are also involved in the incidence of early or late developmental abnormalities such as developmental block, lack of compaction of the morula (Van Soom et al., 1996), abortion, or large calf syndrome (Leese et al., 1998; Van Wagtendonck-de Leeuw et al., 1998; Khosla et al., 2001).

Several factors related to the culture conditions might be at the origin of such abnormal development. Amongst others is the oxidative stress generated by an imbalance between the generation and the destruction of reactive oxygen species (ROS, Halliwell and Gutteridge, 1989). As somatic cells, embryonic cells continuously produce ROS through mitochondrial respiration or cytosolic oxidases (for a review, see Guérin et al., 2001). These ROS are inactivated by antioxidant mechanisms. Cellular antioxidants include enzymatic systems (superoxide dismutase, catalase, peroxydases, ...) and nonenzymatic compounds (glutathione, thioredoxine, chelators,...). Most antioxidant systems seem present in embryonic cells but, during in vitro culture, embryos are exposed to higher levels of ROS generated by their exposure to atmospheric oxygen, light, or traces of metallic ions. Moreover, in vitro embryos lack the maternal protection conferred by oviductal and uterine secretions. Consequently, in vitro produced embryos have, on average, a higher content in ROS than their in vivo counterparts (Nasr-Esfahani et al., 1990; Goto et al., 1993; Johnson and Nasr-Esfahani, 1994; Guérin et al., 2001; Harvey et al., 2002).

In a previous work (Feugang et al., 2003), we have shown that exposure of bovine morulae to ROS through the addition of 2,2'-azobis (2-amidinopropane) dihydrochloride (AAPH; Niki, 1990), a generator of alkyl radicals, or through the inhibition of glutathione synthesis by buthionine sulfoximine (BSO) led to the delayed degeneration of part of the blastocysts. Such degeneration was only observed at day 8 whereas morulae were exposed from day 5 post-insemination (pi). At day 7, the putative day of transfer, no morphological

Grant sponsor: Communauté Française de Belgique-Action de Recherches Concertées; Grant number: 02/07-275.

*Correspondence to: Prof. Isabelle Donnay, Unité des Sciences vétérinaires, Institut des Sciences de la Vie, Université catholique de Louvain, Place Croix du Sud 5 Bte 10, B-1348 Louvain-la-Neuve, Belgium. E-mail: donnay@vete.ucl.ac.be

Received 8 September 2004; Accepted 2 February 2005

Published online 1 April 2005 in Wiley InterScience

(www.interscience.wiley.com).

DOI $10.1002 / \mathrm{mrd} .20262$ 
changes could be observed although an increase in apoptosis and a decrease in glutathione content were described in some conditions (Feugang et al., 2003). The blastocysts resisting to this oxidative stress displayed similar hatching rates and cell numbers than control embryos not exposed to ROS. Thus, the treatment led to the discrimination between two populations, one resisting and one sensitive to oxidative stress.

The objective of the present work was to further characterize both populations. First, using time-lapse cinematography, we analyzed the kinetics of degeneration of the embryos exposed to the two pro-oxidant agents and determined, retrospectively, some characteristics of the embryos resistant or sensitive to these oxidative stress. The profile of protein neosynthesis during the exposure to oxidative stress was also analyzed. In a second set of experiments, we evaluated the sex ratio and the rate of apoptosis in the resisting population.

\section{MATERIALS AND METHODS}

Chemicals were purchased from Sigma-Aldrich (Steinheim, Germany) unless otherwise indicated.

\section{In Vitro Production of Embryos}

Embryos were produced as previously described by Donnay et al. (2002). Briefly, immature cumulus-oocyte complexes (COCs) were obtained by aspirating follicles from 2 to $8 \mathrm{~mm}$ from the ovaries of slaughtered cows. Following maturation for $24 \mathrm{hr}$ in TCM-1999 supplemented with $10 \%(\mathrm{v} / \mathrm{v})$ heat-treated fetal calf serum (FCS) and $10 \mathrm{ng} / \mathrm{ml}$ epidermal growth factor (EGF) oocytes were inseminated with frozen-thawed bull semen, a motile sample of which had been obtained using a Percoll density gradient. Gametes were coincubated for $18-20 \mathrm{hr}$ at $39^{\circ} \mathrm{C}$ in $5 \% \mathrm{CO}_{2}$ in humidified air. Presumptive zygotes were denuded and cultured under paraffin oil in $30 \mu \mathrm{l}(1$ embryo/ $\mu \mathrm{l})$ droplets of modified synthetic oviduct fluid (SOF) according to Holm et al. (1999) containing $0.7 \mathrm{mM}$ Na-pyruvate, $4.2 \mathrm{mM}$ Na-lactate, $2.8 \mathrm{mM}$ myo-inositol, $0.2 \mathrm{mM}$ glutamine (Gibco, Paisley, Scotland), $0.3 \mathrm{mM}$ citrate, $30 \mathrm{ml} / \mathrm{L}$ essential amino acids mixture, $10 \mathrm{ml} / \mathrm{L}$ nonessential amino acids, $50 \mu \mathrm{g} / \mathrm{ml}$ gentamycin, and $5 \%$ (v/v) FCS. Culture was performed in a humidified atmosphere of $5 \% \mathrm{CO}_{2}, 5 \% \mathrm{O}_{2}$, and $90 \% \mathrm{~N}_{2}$ at $39^{\circ} \mathrm{C}$. At day 5 pi (day $0=$ fertilization), morulae were collected for experiments.

\section{Experiment 1: Kinetics of Embryo Degeneration and Characteristics of the Resisting and Degenerating Populations}

Stock solutions of $1 \mathrm{mM}$ AAPH (Interchim, Montluçon, France) and $10 \mathrm{mM}$ BSO were prepared in culture medium then filtered $(0.22 \mu \mathrm{m})$, aliquoted, and stored at $-80^{\circ} \mathrm{C}$ until use. The day of use the working concentrations were obtained by dilution of the stock solutions. Morulae were exposed to $0.01 \mathrm{mM}$ AAPH or $0.4 \mathrm{mMBSO}$ from day 5 pi. Droplets of $20 \mu$ containing 15 morulae were filmed by time-lapse cinematography. To perform time-lapse cinematography embryos were incubated in a culture dish placed in a small chamber on the plate of an inverted microscope (Zeiss, Oberkochen, Germany). The chamber was flushed with a humidified and warmed gas mixture consisting of $5 \% \mathrm{CO}_{2}, 5 \% \mathrm{O}_{2}, 90 \% \mathrm{~N}_{2}$. To maintain a constant temperature of $39^{\circ} \mathrm{C}$, a Plexiglas box was adapted to fit onto the microscope and connected to a heating system controlled by a temperature probe. The recording equipment consisted of a color video camera (JVC, Heta, Japan) and two computers. The first computer synchronizes the lighting of the lamp and the shooting. The second one digitizes and records the frames with the program Perception Video Recorder (Alpha M, Grez-Doiceau, Belgium). One image was recorded every $240 \mathrm{sec}$. Development of the embryos was filmed for 3 days. Only the embryos visible in the camera field throughout the culture period were examined. As a control, embryos of the same origin were simultaneously cultured in the usual incubator. Embryos showing at the end of the culture period a complete collapse of the blastocoele cavity with cell debris inside the zona pellucida (ZP) or in the culture drop (for hatched embryos) were considered as degenerated. For each prooxidant three movies were performed. The external diameter of the $\mathrm{ZP}$ at the morula stage, the timing of appearance of the blastocoele cavity, the start of blastocyst expansion and, when relevant, the first signs of blastocyst degeneration were recorded.

\section{Experiment 2: Protein Neosynthesis in Blastocysts Exposed From Day 5 to Prooxidant Agents}

Groups of five day 7 blastocysts exposed from day 5 to $0.01 \mathrm{mM}$ AAPH or $0.4 \mathrm{mM}$ BSO were collected, washed twice in PBS supplemented with $36 \mathrm{mg} / \mathrm{ml}$ pyruvate and $0.5 \mathrm{mg} / \mathrm{ml}$ BSA (fraction V), and transferred to Eppendorf tubes containing $100 \mu \mathrm{l}$ of labeling solution (PBS supplemented with $1 \mathrm{mCi}$ L- $\left[{ }^{35} \mathrm{~S}\right]$ methionine/ml; Express Protein Labeling Mix, Perkin-Elmer, Boston, MA). Incubation was performed for $3 \mathrm{hr}$ at $39^{\circ} \mathrm{C}$. Embryos were then washed in PBS without BSA and lyzed in $15 \mu$ l Laemmli buffer (Laemmli, 1970) containing $125 \mathrm{mM}$ Tris, $5 \% \mathrm{Na}$ dodecylsulfate (SDS), 25\% glycerol, and $10 \% \beta$-mercaptoethanol at $\mathrm{pH}$ 6.8. The samples were then warmed at $100^{\circ} \mathrm{C}$ for $3 \mathrm{~min}$ and stored at $-20^{\circ} \mathrm{C}$ until use. Protein extracts were then loaded on $10 \%$ SDS-PAGE mini gels. Electrophoresis was performed for $90 \mathrm{~min}$ in two steps: $10 \mathrm{~min}$ at $50 \mathrm{~V}$, then $80 \mathrm{~min}$ at $150 \mathrm{~V}$ at $10 \mathrm{~mA}$. Gels were then incubated under mild agitation for $30 \mathrm{~min}$ in a solution of amplification (Amplify, Amersham Pharmacia Biotech, Little Chalfont, UK) dried for $60 \mathrm{~min}$ at $80^{\circ} \mathrm{C}$ and exposed on film (Hyperfilm MP, Amersham) for 1015 days at $-70^{\circ} \mathrm{C}$. The whole experiment was repeated six times with two different batches of embryos.

\section{Experiment 3: Detection of Apoptosis by the TUNEL Technique in Surviving Day 8 Blastocysts}

The aim of the experiment was to evaluate a possible impact of prooxidants on the level of apoptosis in nondegenerated embryos. Morulae were exposed to 
$0.4 \mathrm{mM}$ BSO or $0.01 \mathrm{mM}$ AAPH from day 5 pi. At day 8 pi, nondegenerated blastocysts were collected for the evaluation of apoptotic rate by the TdT-mediated dUTP Nick-End-Labeling (TUNEL) technique using the In Situ Cell Death Detection Kit (Boehringer Mannheim, Germany). Control untreated blastocysts of the same age were evaluated in parallel.

Briefly, embryos were fixed in $4 \%$ paraformaldehyde in PBS at ambient temperature for $20 \mathrm{~min}$, washed twice in PBS/PVP and permeabilized for 5 min with $0.5 \%$ Triton X-100 in PBS. Subsequently embryos were incubated in dUTP conjugated with rhodamine and TdT for $1 \mathrm{hr}$ at $38^{\circ} \mathrm{C}$ in the dark. Negative controls were incubated in fluorescent-dUTP in the absence of TdT and positive controls were incubated in mouse DNase $(50 \mu \mathrm{g} / \mathrm{ml})$ for $1 \mathrm{hr}$ at $38^{\circ} \mathrm{C}$ and washed before TUNEL. TUNEL reactions were stopped by incubating the embryos in PBS containing 0.5\% BSA. Embryos were then counter-stained with $10 \mu \mathrm{g} / \mathrm{ml}$ of Hoechst (Calbiochem, Schwalbach, Germany) and mounted with cover-slip compression in VectaShield antibleaching solution (Vector Labs, Burlingame, CA). Fluorescent nuclei were counted using a Nikon fluorescence microscope (Hoechst staining: excitation at $330-380 \mathrm{~nm}$, barrier filter at $420 \mathrm{~nm}$; Rhodamine staining: excitation at $510-560 \mathrm{~nm}$, barrier filter at $590 \mathrm{~nm}$ ). The total number of nuclei and the number of TUNEL + nuclei were counted in each embryo.

\section{Experiment 4: Effect of the Sex of the Embryo on Their Resistance to Oxidative Stress}

Both degenerated and nondegenerated day 8 blastocysts treated for 3 days with $0.01 \mathrm{mM}$ AAPH or $0.4 \mathrm{mM}$ BSO as well as control untreated blastocysts were collected, washed, and stored individually at $-80^{\circ} \mathrm{C}$ until use. Sexing was performed using the technique described by Grisart et al. (1995). Briefly, each embryo was heated for $45 \mathrm{~min}$ at $37^{\circ} \mathrm{C}$ in $15 \mu \mathrm{l}$ of lysis buffer (15 mM Tris-HCl, $50 \mathrm{mM} \mathrm{KCl,} 2.5 \mathrm{mM} \mathrm{MgCl} 2,0.1 \%$ Triton-X 100, and $150 \mu \mathrm{g} / \mathrm{ml}$ proteinase $\mathrm{K}, \mathrm{pH}$ 8.9). Then proteinase $\mathrm{K}$ was inactivated $10 \mathrm{~min}$ at $99^{\circ} \mathrm{C}$. Five microliters of the lysate was used for sexing allowing to sex at least twice the same embryo. Y specific primers corresponded to a portion of the satellite sequence btDYZ-1 specific of the Y bovine chromosome (Perret et al., 1990). The primers (sense 5'-GGCGACTGTGCAACYRGT- $3^{\prime}$ and antisense 5'-AGGGCACAGGGCTGAGAA-3 ${ }^{\prime}$ ) have been designed to amplify a TG-rich stretch with variable lengths leading to the formation of a smear characteristic of the male embryo. Another pair of primers was simultaneously used (sense 5'-TATTTTCGGAACGCGGGAGAGAAGAG- 3 ' and antisense $5^{\prime}$-TATTTTTGATTCCCTCCGTGCGGCGCTTA-3') to amplify a $350 \mathrm{bp}$ autosomal band (btRep-137) as a proof of the amplification of each embryo sample, whatever the sex.

Amplification was performed in a final volume of $50 \mu \mathrm{l}$ containing $20 \mathrm{mM}$ Tris- $\mathrm{HCl} \mathrm{pH} 8.5,2 \mathrm{mM} \mathrm{MgCl}_{2}, 25 \mathrm{mM}$ $\mathrm{KCl}$, and $200 \mu \mathrm{M}$ of each nucleotide with $70 \mathrm{ng}$ of $\mathrm{Y}$ specific primers and $6 \mathrm{ng}$ of autosomal primers, $1.25 \mathrm{U}$ of Hot Star Taq DNA polymerase (Qiagen, Hilden,

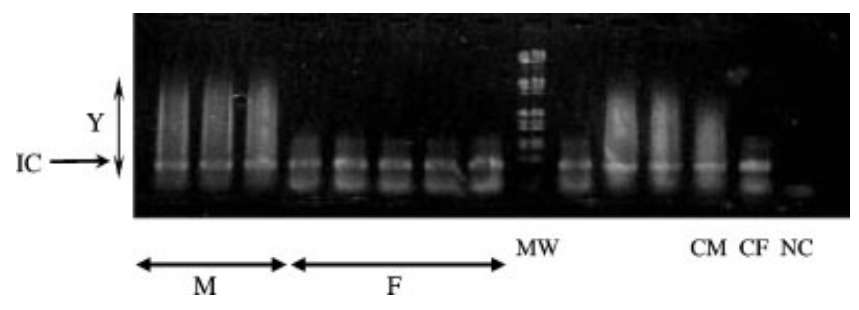

Fig. 1. Agarose gel after co-amplification of $\mathrm{Y}$ specific sequences (Y) and internal control (IC). MW, molecular weight standards; M, male embryos; F, female embryos, CM, control male DNA; CF, control female DNA; NC, negative control.

Germany). After a hot start of $15 \mathrm{~min}$ at $95^{\circ} \mathrm{C}$, ten cycles including $30 \mathrm{sec}$ at $96^{\circ} \mathrm{C}, 30 \mathrm{sec}$ at $48^{\circ} \mathrm{C}$, and $90 \mathrm{sec}$ at $72^{\circ} \mathrm{C}$ were run and followed by 30 cycles with $15 \mathrm{sec}$ at $97^{\circ} \mathrm{C}, 15 \mathrm{sec}$ at $52^{\circ} \mathrm{C}$, and $30 \mathrm{sec}$ at $72^{\circ} \mathrm{C}$. A final extension step was performed for $5 \mathrm{~min}$ at $72^{\circ} \mathrm{C}$.

Each amplification product was separated on a $1 \%$ agarose gel (Gibco) and visualized under UV light after staining with ethidium bromide. Female embryos only showed a band corresponding to the btRep- 137 sequence whereas male embryos exhibited both the btRep- 137 band and a smear corresponding to the amplification of the satellite Y-specific sequences (Fig. 1).

\section{Statistical Analysis}

One way or two way analysis of variance (ANOVA1 or ANOVA2) were used to compare most kinetics parameter between AAPH and BSO treated embryos or the resisting and degenerating embryos in both treatments as well as the cell numbers and the number or proportion of apoptotic cells. Due to lack of normality in the distribution of the diameters the nonparametric Kruskal-Wallis test, followed by the Mann-Whitney test, was used to compare the initial diameters of resisting and degenerating embryos in both treatments. Developmental rates and proportions of male embryos depending on the treatments were compared using contingency table or $\chi^{2}$.

\section{RESULTS \\ Experiment 1: Kinetics of Embryo Degeneration and Characteristics of the Resisting Population}

Culture in the cinematographic chamber did not impair embryo development compared to culture in a normal incubator (Table 1). Both pro-oxidants, AAPH and BSO, induced the degeneration of some blastocysts, as previously described (Feugang et al., 2003). The timing of appearance of the first signs of degeneration was not different between the two prooxidants (Table 2). However, the duration of the degeneration process was significantly shorter in presence of AAPH than with BSO. On the other hand the resisting blastocysts derived from morulae with a mean diameter higher than the degenerating ones (Fig. 2; Kruskal-Wallis, $P<0.05$ ). The resisting blastocysts exhibited on average the first signs of cavitation before those that will degenerate (ANOVA, $P<0.05$ ) and tended to expand earlier (ANOVA, $P=0.07$ ). 
TABLE 1. Embryo Development and Degeneration in Normal Incubator and in the Cinematographic Chamber

\begin{tabular}{lccccc}
\hline & & & \multicolumn{2}{c}{ Day 8 blastocysts, N (\%) } \\
\cline { 5 - 6 } Treatment & Culture & $\begin{array}{c}\text { Day } 5 \\
\text { morulae }\end{array}$ & Total $^{\mathrm{a}}$ & Surviving $^{\mathrm{b}}$ & Degenerated $^{\mathrm{b}}$ \\
\hline $0.01 \mathrm{mM}$ AAPH & Incubator & 30 & $26(87)$ & $17(65)$ & $9(35)$ \\
\multirow{2}{*}{$0.4 \mathrm{mM}$ BSO } & Chamber & 45 & $38(84)$ & $19(50)$ & $19(50)$ \\
& Incubator & 30 & $23(77)$ & $13(57)$ & $10(43)$ \\
& Chamber & 45 & $41(91)$ & $19(46)$ & $22(54)$ \\
\hline
\end{tabular}

Percentages are calculated on morulae ${ }^{\mathrm{a}}$ or on total blastocysts ${ }^{\mathrm{b}}$. No significant differences were found within columns (contingency table, $P>0.05$ ).

TABLE 2. Initial Diameter of the Morulae and Kinetics of Development and Degeneration of Bovine Blastocysts After 3 Days Exposure to Prooxidant Agents

\begin{tabular}{|c|c|c|c|c|c|c|}
\hline \multirow[b]{2}{*}{ Parameters } & \multirow[b]{2}{*}{$\mathrm{N}$} & \multicolumn{2}{|c|}{ AAPH treatment } & \multirow[b]{2}{*}{$\mathrm{N}$} & \multicolumn{2}{|c|}{ BSO treatment } \\
\hline & & Surviving & Degenerated & & Surviving & Degenerated \\
\hline Diameter of morulae $(\mu \mathrm{m})$ & 38 & $161 \pm 1^{\mathrm{a}}$ & $156 \pm 1^{\mathrm{b}}$ & 38 & $161 \pm 2^{\mathrm{a}}$ & $152 \pm 1^{\mathrm{b}}$ \\
\hline Timing of cavitation (hpi) & 38 & $134 \pm 1^{\mathrm{a}}$ & $141 \pm 2^{b}$ & 38 & $136 \pm 2^{\mathrm{a}}$ & $143 \pm 2^{b}$ \\
\hline Beginning of expansion (hpi) & 38 & $145 \pm 2^{\mathrm{a}}$ & $152 \pm 4^{\mathrm{a}}$ & 38 & $144 \pm 2^{\mathrm{a}}$ & $149 \pm 2^{\mathrm{a}}$ \\
\hline \multicolumn{7}{|l|}{ Degeneration } \\
\hline First signs (hpi) & 19 & & $180 \pm 2^{\mathrm{c}}$ & 19 & & $180 \pm 2^{\mathrm{c}}$ \\
\hline Completed (hpi) & 19 & & $183 \pm 2^{\mathrm{c}}$ & 19 & & $190 \pm 2^{\mathrm{d}}$ \\
\hline Duration $(\mathrm{hr})$ & 19 & & $4.2 \pm 0.9^{\mathrm{c}}$ & 19 & & $12.5 \pm 1.3^{\mathrm{d}}$ \\
\hline
\end{tabular}

${ }^{\text {a,b }}$ Significant difference between surviving and degenerating embryos within the same row (ANOVA2, $P<0.05$ ).

${ }^{\mathrm{c}, \mathrm{d}}$ Significant difference between the two prooxidants within the same row (ANOVA1, $P<0.05$ ).

\section{Experiment 2: Protein Neosynthesis in Blastocysts Exposed From Day 5 to Prooxidant Agents}

Protein neosynthesis was analyzed at the morula stage (day $5 \mathrm{pi}$, before treatment) and at the blastocyst stage after 2 days of exposure (day 7 pi) but before blastocyst degeneration.

A representative gel is showed in Figure 3. Each lane represents a pool of five embryos. The transition from the morula (lane A) to the blastocyst stage (untreated

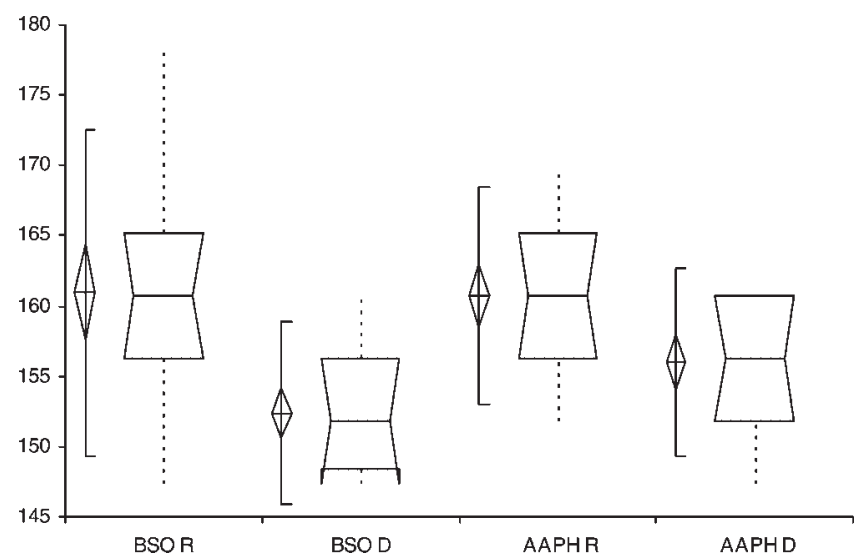

Fig. 2. Box plots representing the distribution of the initial diameters $(\mu \mathrm{m})$ of the morulae in relation with the survival of the resulting blastocyst to AAPH or BSO treatment. BSO R, embryos surviving to BSO; AAPH R, embryos surviving to AAPH; BSO D, embryos degenerated after BSO exposure; AAPH D, embryos degenerated after AAPH exposure.

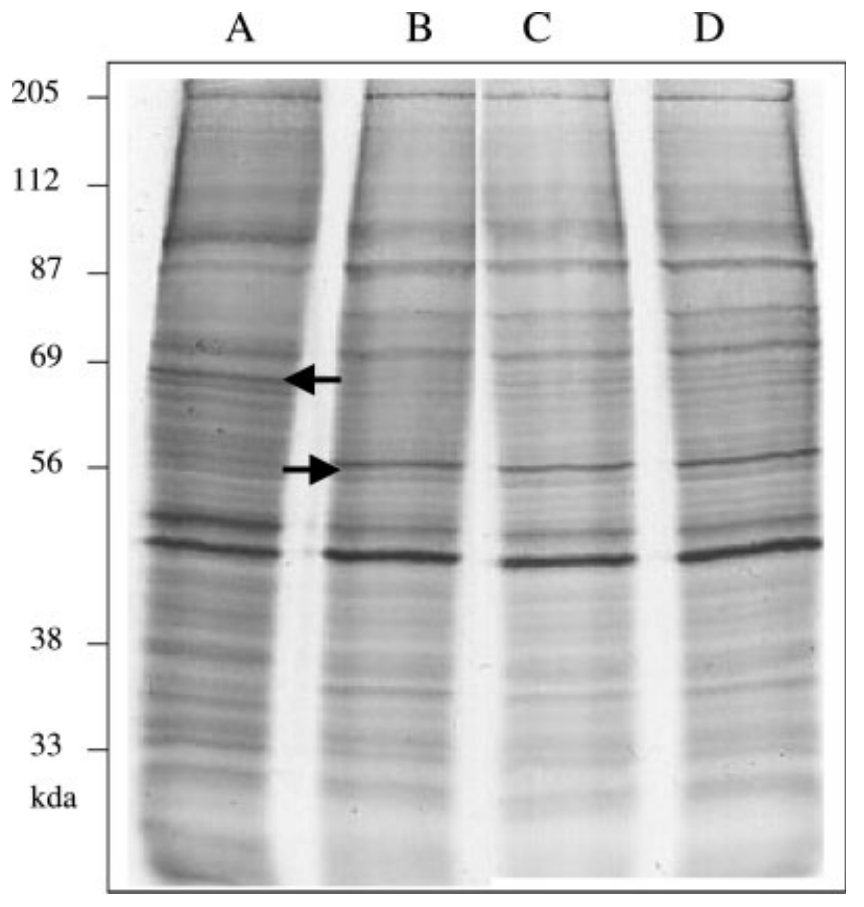

Fig. 3. Autoradiography of a SDS-PAGE gel after labeling of bovine embryos for $3 \mathrm{hr}$ with $\mathrm{S}^{35}$ methionine. Each lane corresponds to five embryos. Morulae were collected at day 5 (lane A) and cultured for $48 \mathrm{hr}$ with or without pro-oxidants. Lane B: Control day 7 blastocysts; (lane C) day 7 blastocysts incubated with $0.01 \mathrm{mM} \mathrm{AAPH}$; (lane D) day 7 blastocysts incubated with $0.4 \mathrm{mM}$ BSO. Arrows indicate bands of 58 and $68 \mathrm{kDA}$. 
TABLE 3. Effect of Prooxidants on the Total Cell Number and Proportion of TUNEL Positive Nuclei in Surviving Day 8 Blastocysts After 3 Days of Treatment

\begin{tabular}{|c|c|c|c|c|}
\hline \multirow[b]{3}{*}{ Treatment } & \multicolumn{4}{|c|}{ Day 8 surviving blastocysts ${ }^{a}$} \\
\hline & \multirow[b]{2}{*}{$\mathrm{N}$} & \multirow{2}{*}{$\begin{array}{l}\text { Total cell } \\
\text { number }\end{array}$} & \multicolumn{2}{|c|}{ TUNEL + nuclei } \\
\hline & & & $\mathrm{N}$ & $\%$ \\
\hline Control & 33 & $126 \pm 6$ & $7.4 \pm 0.6$ & $6.1 \pm 0.6$ \\
\hline $0.01 \mathrm{mM}$ AAPH & 35 & $121 \pm 6$ & $7.1 \pm 0.6$ & $6.0 \pm 0.6$ \\
\hline $0.4 \mathrm{mM} \mathrm{BSO}$ & 33 & $119 \pm 6$ & $8.9 \pm 0.6$ & $7.9 \pm 0.6$ \\
\hline
\end{tabular}

Data between treatments are not significantly different within columns $(P>0.05$; ANOVA 2$)$.

${ }^{a}$ Data are expressed as means \pm SEM.

control, lane B) is characterized by qualitative and quantitative variations in protein neosynthesis. Major differences concern the systematic disappearance of a $68 \mathrm{kDa}$ band and the appearance of a $58 \mathrm{kDa}$ band in day 7 blastocysts. However, no obvious differences were observed between embryos treated with pro-oxidant agents (AAPH: land C; BSO: lane D) and untreated embryos of the same age (lane B).

\section{Experiment 3: Detection of Apoptosis by TUNEL Technique in Surviving Day 8 Blastocysts}

The number and proportion of TUNEL positive nuclei were analyzed on surviving day 8 blastocysts treated with both pro-oxidants. The total cell number and the proportion of TUNEL + nuclei did not differ significantly between the two treatments and the untreated embryos of the same age (Table 3 ).

\section{Experiment 4: Effect of the Sex of the Embryo on the Resistance to Oxidative Stress}

Results are summarized in Table 4 . The proportion of males for untreated day 8 blastocysts coming from the same culture dishes as treated embryos was 57\% (20/35) and did not differ from the whole population sorted at day $5(159 / 261,61 \%)$.

A significant increase in the proportion of male embryos was observed among embryos resisting to the oxidative stress $(70 \%)$ compared with the degenerated ones $\left(55 \%, \chi^{2}, P=0.03\right)$. This increase was only significant for AAPH treated embryos $\left(\chi^{2}, P=0.04\right)$.

\section{DISCUSSION}

We have previously shown that exposure of bovine IVP morulae from day 5 pi to AAPH or BSO did not impair subsequent embryonic development up to the blastocyst stage, however, it induced a delayed degeneration of some blastocysts starting at day $7.5 \mathrm{pi}$ (Feugang et al., 2003).

In this study, using time-lapse cinematography, we characterized the kinetics of this embryonic degeneration and determined, retrospectively, features of the degenerating and resisting embryos. Embryo culture in the time-lapse chamber did not affect the developmental rate and the proportion of degenerated embryos after treatment with the two pro-oxidant agents. Both prooxidants induced the first signs of blastocyst degeneration at the same time on day $7.5 \mathrm{pi}(180 \mathrm{hpi}), 60 \mathrm{hr}$ after the start of the treatment ( $120 \mathrm{hpi}$ ). We have previously shown that such a delayed degeneration was not related to a cumulative effect of the pro-oxidants but more likely to a higher sensitivity of the expanding blastocysts (Feugang et al., 2003). The process of degeneration lasted longer with BSO than with AAPH (12.5 vs. $4.2 \mathrm{hr}$ ). This could be explained by the mechanisms of action of the two pro-oxidants. Indeed AAPH produces free radicals in the culture medium that directly react with cell membranes and induce a cascade of lipid peroxidations leading to an exponential increase in ROS (Niki, 1990). On the contrary, BSO inhibits de novo synthesis of glutathione. The progressive decrease in the intracellular pool of glutathione affects embryonic antioxidant defenses both directly and by preventing the regeneration of oxidized antioxidant enzymes like glutathione peroxidases or peroxiredoxin 6 . It affects the redox status of the cell and protein or DNA synthesis. In presence of BSO, a significant decrease in the oxygen uptake by nondegenerated day 7 blastocysts was observed (Genicot and Donnay, unpublished) indicating perturbations in the mitochondrial function.

The retrospective analysis of the two populations of embryos, degenerating and resisting ones, revealed that resisting embryos derived from morulae with a significantly higher diameter. Furthermore, the resisting

TABLE 4. Effect of 3 Days Exposure to Pro-Oxidants on the Sex Ratio of the Surviving and Degenenerated Blastocysts at Day 8 Post-Insemination (pi)

\begin{tabular}{|c|c|c|c|c|c|}
\hline \multirow[b]{3}{*}{ Embryos sorted at day 5} & \multicolumn{5}{|c|}{ Sex ratio of day 8 blastocysts } \\
\hline & \multirow[b]{2}{*}{ Males/total $(\%)$} & \multicolumn{2}{|c|}{ Surviving } & \multicolumn{2}{|c|}{ Degenerated } \\
\hline & & $\mathrm{N}$ & Males (\%) & $\mathrm{N}$ & Males (\%) \\
\hline Control & $34 / 58(59)$ & 58 & $34(59)$ & 0 & - \\
\hline $0.01 \mathrm{mM}$ AAPH & $70 / 112(63)$ & 57 & $41(72)^{\mathrm{a}}$ & 55 & $29(53)^{b}$ \\
\hline $0.4 \mathrm{mM}$ BSO & $55 / 91(60)$ & 33 & $22(67)^{\mathrm{a}}$ & 58 & $33(57)^{\mathrm{a}}$ \\
\hline Total & $159 / 261(61)$ & & & & \\
\hline
\end{tabular}

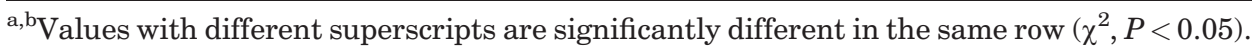


blastocysts were characterized by an earlier cavitation and tended to expand earlier than their degenerating counterparts. As similar results were obtained with both pro-oxidants, it probably indicates differences in the overall sensitivity to oxidative stress. To our knowledge, it is the first time that the morula diameter is associated with the quality of the resulting blastocyst. As the embryo diameter remains stable from the oocyte up to the early blastocyst stage, one might speculate that the difference in diameter observed at the morula stage was already present at the oocyte stage. Oocyte diameter has been correlated with competence for nuclear maturation (De Smedt et al., 1994) and for early development following fertilization (Crozet et al., 1995; Fair et al., 1995). A positive correlation between oocyte and follicle sizes has been demonstrated (Fair et al., 1995). Oocytes from large follicles have a better developmental competence and embryos derived from these oocytes exhibit an earlier cavitation process than those derived from small follicles (Lequarre et al., 2005). Moreover, early cavitating IVP blastocysts are also more resistant to cryopreservation (Massip et al., 1995; Donnay et al., 1998; Dinnyès et al., 1999; Kaidi et al., 2000) and have better pregnancy outcome (Hasler et al., 1995). Such higher quality might be explained, at least partly, by better intercellular junctions. Choosing oocytes or morulae with a higher mean diameter might thus help to select IVP embryos of better quality for manipulations and transfer. A prospective study is nevertheless necessary to confirm such correlation. No clear cut off exists, however, between the diameters of the resisting and degenerating populations of blastocysts (Fig. 3) preventing the selection of the "best" embryos on this basis only.

Male embryos seem more resistant to oxidative stress, especially when induced by AAPH, than female ones. Several studies indicated that male embryos predominate among in vitro produced bovine blastocysts $(\mathrm{Xu}$ et al., 1992; Lonergan et al., 1999). In presence of glucose male embryos have a better ability to go through the morula-blastocyst transition (Larson et al., 2001), it is apparently also the case when serum is added to the culture medium (Gutiérrez-Adan et al., 2000). Under our culture conditions (5\% FCS but no added glucose) day 8 blastocysts are predominantly male in the control group but this shift seemed reinforced by oxidative stress. King et al. (1992) suggested that male embryos are less sensitive than female ones to the stress induced by manipulations such as variations in temperature. It is also known that male IVP embryos often expand earlier or faster than female ones (Yadav et al., 1993; Grisart et al., 1995; Carvalho et al., 1996; GutiérrezAdan et al., 1996; Lonergan et al., 1999; Larson et al., 2001). The correlation between male gender and early expansion makes difficult to specify if it is the sex or the characteristics of expansion that is related to the resistance to oxidative stress.

Up to now no convincing hypothesis can be proposed to explain the differences between male and female IVP embryos. The expression of some Y-chromosome genes may enhance male development but the major contributing factor to sexual dimorphism among early embryos appears to be a double dosage of X-linked genes (Peippo et al., 2002; Wrenzycki et al., 2002). Indeed Xchromosome inactivation is only initiated at the blastocyst stage in bovine embryos (De La Fuente et al., 1999). G6PDH is one these $X$-linked genes. It is the ratelimiting enzyme of the pentose phosphate pathway leading to the cellular production of NADPH (Rieger, 1992; Filosa et al., 2003) referred to as the guardian of the cell redox state. The levels of G6PDH RNA are higher in female morulae and blastocysts (GutiérrezAdan et al., 2000; Peippo et al., 2002). A higher level of this gene in female embryos should give them a better resistance to oxidative stress but this is not what we observed here. However, a higher activity of the pentose phosphate pathway can have unexpected consequences as showed recently by Kimura et al. (2004) who demonstrated its correlation with an increased production of interferon tau in female embryos.

Twelve hours before the first signs of degeneration the profile of protein neosynthesis was not obviously different between blastocysts exposed for 2 days to prooxidant agents and control blastocysts of the same age. The technique used here did not allow to detect subtle changes but the results indicate that oxidative stress did not deeply affect protein synthesis and changes in protein neosynthesis are unlikely to be the main cause of blastocyst degeneration $12 \mathrm{hr}$ later. Interestingly, we observed differences in protein synthesis between day 5 morulae and day 7 blastocysts. To our knowledge, such differences were not previously described in bovine embryos. Frei et al. (1989), for example, did not see changes in the profiles of protein neosynthesis between the 16 to 32 -cell and the blastocyst stages. These proteins may be involved in the morphological changes (cavitation, cell junctions) or metabolic changes (glucose metabolism) occurring during morula to blastocyst stage transition. Further studies are, however, necessary to identify the proteins corresponding to the 68 and $58 \mathrm{kDa}$ bands that showed the most obvious changes in our conditions.

Total cell number and the proportion of apoptotic nuclei detected by the TUNEL technique were not different between blastocysts resisting to oxidative stress at day 8 and control blastocysts of the same age. Moreover, we previously showed that hatching rates were not affected (Feugang et al., 2003). The quality of resisting embryos using those limited criteria seems unaffected by the treatment. Paradoxically a significant increase in the number and proportion of TUNEL positive nuclei was observed 1 day before (Feugang et al., 2003). Although, it is difficult to prove, it is possible that the general increase in apoptosis at day 7 was in fact related mainly to the population of embryos that will degenerate after day 7.5 but was not observed in the population that will resist to oxidative stress. Resistance to the induction of apoptosis by oxidative stress might be related to the level of antiapoptotic factors in the embryonic cells. The antiapoptotic factor Bcl-2 has been 
shown to be present in bovine blastocysts (Kölle et al., 2002; Yang and Rajamahendran, 2002). However, the increase in apoptosis observed at day 7 is unlikely to be at the origin of blastocyst degeneration as it was mainly observed in the ICM cells while the process of degeneration started from the trophectoderm (Feugang et al., 2003).

In conclusion, the artificial induction of an oxidative stress starting at the morula stage allowed the discrimination of two populations of embryos $60 \mathrm{hr}$ later with no obvious alteration in the general profile of protein neosynthesis. The resisting blastocysts derived preferably from morulae with a large diameter, they showed an early cavitation and presented a sex ratio skewed with a higher proportion of males. The quality of the resisting embryos estimated by total cell number and rate of apoptosis did not seem to be affected by this oxidative stress.

\section{REFERENCES}

Avery B, Madison V, Greve T. 1991. Sex and development in bovine in vitro fertilized embryo. Theriogenology 35:953-963.

Carolan C, Lonergan P, Van Langendonckt A, Mermillod P. 1995. Factors affecting bovine embryo development in synthetic oviduct fluid following oocyte maturation and fertilization in vitro. Theriogenology 43:1115-1128.

Carvalho RV, Del campo MR, Palasz AT, Plante Y, Mapletoft RJ. 1996. Survival rate and sex ratio of bovine IVF embryos frozen at different developmental stages on day 7. Theriogenology 45:489-498.

Crozet N, Ahmed-Ali M, Dubos MP. 1995. Developmental competence of goat oocytes from follicles of different size categories following maturation, fertilization and culture in vitro. J Reprod Fertil 103: 293-298.

De La Fuente R, Hahnel A, Basrur PK, King WA. 1999. X inactive-specific transcript (Xist) expression and $\mathrm{X}$ chromosome inactivation in the preattachment bovine embryo. Biol Reprod 60:769-775.

De Smedt V, Crozet N, Gall L. 1994. Morphological and functional changes accompanying the acquisition of meiotic competence in ovarian goat oocyte. J Exp Zool 269:128-139.

Dinnyès A, Lonergan P, Fair T, Boland MP, Yang X. 1999. Timing of the first cleavage post-insemination affects cryosurvival of in vitroproduced bovine blastocysts. Mol Reprod Dev 53:318-324.

Donnay I, Auquier P, Kaidi S, Carolan C, Lonergan P, Mermillod P, Massip A. 1998. Vitrification of in vitro produced bovine blastocysts: Methodological studies and developmental capacity. Anim Reprod Sci 52:93-104.

Donnay I, Feugang JM, Bernard S, Marchandise J, Pampfer S, Moens A, Dessy F. 2002. Impact of adding $5.5 \mathrm{mM}$ glucose to SOF medium on the development, metabolism, and quality of in vitro produced bovine embryos from the morula to the blastocyst stage. Zygote 10:189199

Fair T, Hyttel P, Greve T. 1995. Bovine oocyte diameter in relation to maturational competence and transcriptional activity. Mol Reprod Dev 42:437-442

Feugang JM, Van Langendonckt A, Sayoud H, Rees JF, Pampfer S, Moens A, Dessy F, Donnay I. 2003. Effect of prooxidant agents added at the morula/blastocyst stage on bovine embryo development, cell death, and glutathione content. Zygote 11:107-118.

Filosa S, Fico A, Paglialunga F, Balestrieri M, Crooke A, Verde P, Abrescia P, Bautista JM, Martini G. 2003. Failure to increase glucose consumption through the pentose-phosphate pathway results in the death of glucose- 6 phosphate gene-deleted mouse embryonic stem cells subjected to oxidative stress. Biochem J 370:935-943.

Frei RE, Schultz GA, Church RB. 1989. Qualitative and quantitative changes in protein synthesis occur at the 8-16 cell stage of embryogenesis in the cow. J Reprod Fertil 86:637-641.
Goto Y, Noda Y, Mori T, Nakano M. 1993. Increased generation of reactive oxygen species in embryo cultured in vitro. Free Rad Biol Med 15:69-75.

Grisart B, Massip A, Collette L, Dessy F. 1995. The sex ratio of bovine embryos produced in serum-free oviduct-conditioned medium is not altered. Theriogenology 43:1097-1106.

Gutiérrez-Adan A, Behboodi E, Anderson GB, Medrano JF, Murray JD. 1996. Relationship between stade of development and sex of bovine IVM-IVF embryos cultured in vitro versus in the sheep oviduct. Theriogenology 46:515-525.

Gutiérrez-Adan A, Oter M, Martinez-Madrid B, Pintado B, De La Fuente J. 2000. Differential expression of two genes located on the $\mathrm{X}$ chromosome between male and female in vitro produced bovine embryos at the blastocyste stage. Mol Reprod Dev 55:146-151.

Guérin P, El Mouatassim S, Ménézo Y. 2001. Oxidative stress and protection against reactive oxygen species in the pre-implantation embryo and its surroundings. Human Reprod Update 7:175-189.

Halliwell B, Gutteridge JMC. 1989. The chemistry of oxygen radicals and other derived species. In: Halliwell B, Gutteridge JMC, editors. Free radical biology and medicine. 2nd edition. Oxford: Clarenton Press. pp 22-85.

Harvey AJ, Kind KL, Thompson JG. 2002. REDOX regulation of early embryo development. Reproduction 123:479-486.

Hasler JF, Henderson WB, Hurtgens PJ, Jin ZQ, McCauley AD, Mower SA, Neely B, Shuey LS, Stokes JE, Trimmer SA. 1995. Production, freezing, and transfer of bovine IVF embryos and subsequent calving results. Theriogenology 43:141-152.

Holm P, Booth P, Schmidt MH, Greve T, Callesen H. 1999. High bovine blastocyst development in a static in vitro production system using SOFaa medium supplemented with sodium citrate and myo-inositol with or without serum-proteins. Theriogenology 52:683-700.

Johnson MH, Nasr-Esfahani MH. 1994. Radical solutions and cultural problems: Could free oxygen radicals be responsible for impaired development of preimplantation mammalian embryos in vitro? BioEssays 16:31-38

Kaidi S, Donnay I, Lambert P, Dessy F, Massip A. 2000. Osmotic behavior of in vitro produced bovine blastocysts in cryoprotectant solutions as a potential predictive test of survival. Cryobiology 41:106-115.

Khosla S, Dean W, Reik W, Freil R. 2001. Epigenetic and experimental modifications in early mammalian development: Part II-Culture of preimplantation embryos and its long-term effects on gene expression and phenotype. Human Reprod Update 7:419-427.

Kimura K, Spate LD, Green MP, Roberts RM. 2004. Effects of oxidative stress and inhibitors of the pentose phosphate pathway on sexually dimorphic production of IFN-tau by bovine blastocysts. Mol Reprod Dev 68:88-95.

King WA, Picard L, Bousquet D, Goff AK. 1992. Sex-dependent loss of bisected bovine morulae after culture and freezing. J Reprod Fertil 96:453-459.

Kölle S, Stojkovic M, Boie G, Wolf E, Sinowatz F. 2002. Growth hormone inhibits apoptosis in in vitro produced bovine embryos. Mol Reprod Dev 61:180-186.

Laemmli UK. 1970. Cleavage of structural proteins during the assembly of the head of bacteriophage T4. Nature 227:680-685.

Larson M, Kimura K, Kubisch MH, Roberts MR. 2001. Sexual dimorphism among bovine embryos in their ability to make the transition to expanded blastocyst and in the expression of the signaling molecule IFN- $\tau$. PNAS 98:9677-9682.

Leese HJ, Donnay I, Thompson JG. 1998. Human assisted conception A cautionary tale. Lessons from domestic animals. Hum Reprod 13:184-201.

Lequarre AS, Vigneron C, Ribaucour F, Holm P, Donnay I, DalbièsTran R, Callesen H, Mermillod P. 2005. Influence of antral follicle size on oocyte characteristics and embryo development in the bovine. Theriogenology 63:841-859.

Lonergan P, Khatir H, Piumi F, Rieger D, Humblot P, Boland MP. 1999. Effect of time interval from insemination to first cleavage on the developmental characteristics, sex ratio and pregnancy rate after transfer of bovine embryos. J Reprod Fertil 117:159-167.

Massip A, Mermillod P, Dinnyes A. 1995. Morphology and biochemistry of in-vitro produced bovine embryos: Implications for their cryopreservation. Hum Reprod 10:3004-3011. 
Nasr-Esfahani MH, Aitken JR, Johnson MH. 1990. Hydrogen peroxide levels in mouse oocytes and early cleavage stage embryos developed in vitro or in vivo. Development 109:501-507.

Niki E. 1990. Free radical initiators as sources of water- or lipid-soluble peroxyl radicals. Methods Enzymol 186:100-108.

Peippo J, Kurkilahti M, Bredbacka P. 2001. Developmental kinetics of in vitro produced bovine embryos: The effect of sex, glucose, and exposure to time-lapse environment. Zygote 9:105-113.

Peippo JP, Farazmand A, Kurkilahti M, Markkula M, Basrur PK, King WA. 2002. Sex-chromosome linked gene expression in in-vitro produced bovine embryos. Mol Hum Reprod 8:923-929.

Perret J, Shia Y-C, Fries R, Vassart G, Georges M. 1990. A polymorphic satellite sequence maps to the pericentric region of the bovine $\mathrm{Y}$ chromosome. Genomics 6:482-490.

Rieger D. 1992. Relationship between energy metabolism and development of early mammalian embryos. Theriogenology 37 : $75-93$.

Thompson JG, Sherman A, Allen NW, McGowan LT, Tervit HR. 1998. Total protein content and protein synthesis within pre-elongation stage bovine embryos. Mol Reprod Dev 50:139145.

Van Langendonckt A, Donnay I, Schuurbiers N, Auquier P, Carolan C, Massip A, Dessy F. 1997. Effects of supplementation with fetal calf serum on development of bovine embryos in synthetic oviduct fluid medium. J Reprod Fertil 109:87-93.

Van Soom A, Boerjan M, Ysebaert MT, de Kruif A. 1996. Cell allocation to the inner cell mass and the trophectoderm in bovine embryos cultured in two different media. Mol Reprod Dev 45:171-182.

Van Wagtendonck-de Leeuw AM, Aerts BJG, Den Daas JHG. 1998. Abnormal offspring following in vitro production of bovine preimplantation embryos: A field study. Theriogenology 49:883-894.

Wrenzycki C, Lucas-Hahn A, Herrmann D, Lemme E, Korsawe K Niemann H. 2002. In vitro production and nuclear transfer affect dosage compensation of the X-linked gene transcripts G6PD, PGK and Xist in preimplantation bovine embryos. Biol Reprod 66:127134

$\mathrm{Xu}$ KP, Yadav BR, King WA, Betteridge KJ. 1992. Sex-related differences in developmental rates of bovine embryos produced and cultured in vitro. Mol Reprod Dev 31:249-252.

Yadav BR, King WA, Betteridge KJ. 1993. Relationship between the completion of first cleavage and chromosomal complement, sex, and developmental rates of bovine embryos generated in vitro. Mol Reprod Dev 36:434-439.

Yang MY, Rajamahendran R. 2002. Expression of Bcl-2 and Bax proteins in relation to quality of bovine oocytes and embryos produced in vitro. Anim Reprod Sci 70:159-169. 